\title{
SPIRAl Management - NeW CONCEPT OF THE SOCIAL SYSTEMS MANAGEMENT
}

\author{
Justína Mikulášková, Miloš Čambál, Lubošs Polakovič
}
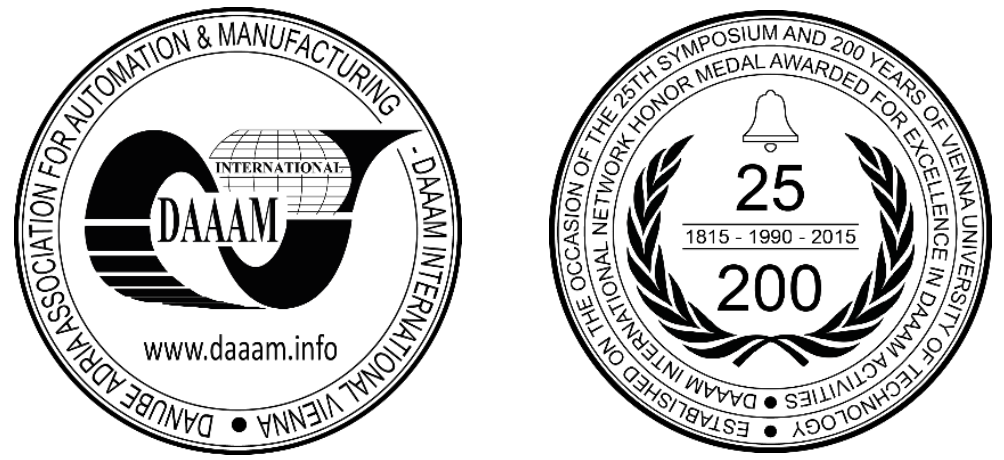

This Publication has to be referred as: Mikulaskova, J[ustina]; Cambal, M[ilos] \& Polakovic, L[ubos] (2018). Spiral Management - A New Concept of the Social Systems Management, Proceedings of the 29th DAAAM International Symposium, pp.0908-0915, B. Katalinic (Ed.), Published by DAAAM International, ISBN 978-3-902734-20-4, ISSN 1726-9679, Vienna, Austria

DOI: $10.2507 / 29$ th.daaam.proceedings.131

\begin{abstract}
Spiral Management and its principles are based on the long-term successful existence of living systems. The principles can be applied to the enterprise and organization management. Living systems manage long-term success by acquiring energy from their surroundings (through nutrition), while enterprises acquire customers and employees' energy in order to eliminate entropy (in enterprises manifested as economic losses). Spiral management is based on the synergy of living systems. It describes behaviour patterns in cyclical development of enterprises as well as ability of the latter to diagnose their own strategic decisions, including the instructions of how to drive an enterprise towards a long-term success. The current paper describes theoretical basis of Spiral Management, while providing a novel insight into this unique managerial approach and emphasising its importance for the human resources management. Also introduced are the elements of Spiral Management applied in the enterprises that want be competitive and survive turbulent periods. This work was supported by the VEGA Project No. 1/0348/17 under the title: "The impact of the coexistence of different generations of employees on the sustainable performance of organisations".
\end{abstract}

Keywords: corporate culture; enterprise management; entropy; new paradigm; social system; spiral management

\section{Introduction}

The world of the 21 st century is characterised by dynamism, turbulence and uncertainty. There is a need for change of the complex paradigm of thinking in society and humanity, as well as in organisations and enterprises at every market level. [3] The current crisis differs from the previous ones; it is a crisis of consciousness, a crisis of paradigm, when the commonly accepted rules and procedures stop working. [6] Companies are struggling with fluctuation, disproportionate cost of production quality, increasing pressure on growth and expansion versus social responsibility, or traditionalism versus multiculturalism etc. A new direction within the economy and society will require a change. The change of society and economy will inevitably necessitate the change at all the levels of enterprise, family and an individual.

The change will always concern the whole enterprise, never just a part of it. Unlike in the situation where it is enough just to survive stormy times, the future will be typical for a degree of adaptation to the new performance requirements that will always follow the change (the cyclicality of turbulent changes). Enterprises should be thus perceived as living organisms or systems. [5] 
Humanity is approaching the moment of transition from the mechanistic paradigm to the holistic one. It is therefore necessary to address the issue of complexity in perceiving an enterprise as a living organism. Comprehensive systems require changes in time affecting the current state of enterprise. The key role of management is to influence, steer and manage an enterprise towards success. A comprehensive system must be influenced. However, managers never know the system absolutely, they just know certain principles; other features may be completely hidden from them. [2] Representing the most important segment of complex systems, people are the major driving force behind the enterprise. Spiral Management is here to offer the tools for the modern management of people, enterprises and organisations. [3] When we are discussing an enterprise - the change has to "touch" the company as the whole - never only part of it. As opposed of the situation when "keep holding" and survive the turbulent time is enough - now it is the time to increase the adaptation rate towards the new requirements of the system environment. It could be called cyclicality within turbulent changes. [8] The enterprise or organization or even a company can be perceived as the living system and the role of the management is to approach them as to living systems. It is necessary to deal the issue of the complexity. And that is mainly because - complex systems need changes in time, while those influence their current state. The main role of the management is to make impact on complex systems. These systems are never fully known. People, as the most important part of complex systems, are the main driving force of all events in a company. [5]

We are living the time when individual areas of knowledge are connected by numerous links (unimaginable in the past), and traditionally established boundaries between disciplines are being erased. Reality does not appear as fragmented and isolated segments; on the contrary, it is perceived as an interconnected whole. When focusing on the whole, we are able to go beyond our current needs, personal interests and momentary obsessions. Such interdisciplinarity and consistency of insight naturally raises the sense of responsibility, shifting the European way of thinking from the classical concept of science, education and progress to the post-classical or post-modernistic one. [1]

\begin{tabular}{|l|l|}
\hline Classical paradigm & Post-classical (postmodern) paradigm \\
\hline Facts & Connections \\
\hline Truth & Significance \\
\hline Features & Symbol, metaphor \\
\hline Analysis & Synthesis \\
\hline Rationality & Intuition, inspiration (role of unconsciousness) \\
\hline Reduction (simplification) & Ambiguity, incomprehensibility \\
\hline Basic building units & Unifying principle \\
\hline Elements & Relationships \\
\hline Static model, mechanism & Vitalism, organicism \\
\hline Sustainability, state of being & Transformation \\
\hline Development, progress, unilinearity & $\begin{array}{l}\text { Plurality of developmental lines, regression, "blind } \\
\text { street" }\end{array}$ \\
\hline Adaptation, competition (“fight for life") & Creativity, collaboration (symbiosis) \\
\hline Purpose & Spontaneity, playfulness, coincidence, chaos \\
\hline Cultivation vs. spontaneity & Permeation of nature and education culture \\
\hline $\begin{array}{l}\text { Isolation of the item under investigation (laboratory } \\
\text { conditions) }\end{array}$ & Inserting into context (natural conditions) \\
\hline Individuality/Particularity, segment of reality & Holistic perception (grasping reality globally) \\
\hline $\begin{array}{l}\text { Unidirectional relationships } \\
\text { hierarchies }\end{array}$ & Feedback, cohesion \\
\hline Subject and object (recognising vs. recognised) & Relativisation of the subject and object's duality \\
\hline Retraction, ab extra view & Engagement \\
\hline Description, explanation & Interpretation, understanding \\
\hline & \\
\hline
\end{tabular}




\begin{tabular}{|l|l|}
\hline Matematisation, abstraction, theory & Literature, practice, experience \\
\hline Science vs. experience & Experience as a source of scientific inspiration \\
\hline Differentiation of scientific disciplines & Interdisciplinarity \\
\hline Unity, universality, majority, standardisation & Diversity, plurality, minorities, exceptions \\
\hline Eurocentrism & Multiculturalism \\
\hline Scientific vs. unscientific & Inspiration by myths, imagination, game \\
\hline Separation of science form public & Popularisation, application, public involvement \\
\hline Independence of science & Ethical, societal and cultural aspects \\
\hline
\end{tabular}

Table 1. Classical vs. Post-classical paradigm of the society [1]

Table 1 indicates the shift expressed as a change of the mechanical, inanimate image of the world modelled according to a perfect and intelligible machine towards the vitalistic concept perceiving the world as a living organism spontaneously manifesting itself, subject to constant change and connected by complex links on various levels. There the role of a scientist is that of an involved observer rather than an independent expert. Such concept is a diversion from the classical division into spiritual and material, and appears to be a natural tendency to adopt the religious and ethical attitudes also in the field of the exact natural sciences. [1] Aim of the paper is to outline the role of New Managerial Concept in todays moved time. Social systems need to be managed by exactly determined rules and procedures reflecting real business world - not only theoretical models never applicated in any company. Main questions arising from this approach are strongly linked on social systems management partial tasks. Entropy as main reason of biological system destruction affects all organizations employing people. The way a company deals with entropy is crucial for its existence. Every social system is creating a particular environment that is mostly called corporate culture. The level and form of corporate culture has very significant impact on company's performance and future direction. Spiral management's way of corporate culture perception is unique and respond to successful employees' management.

\section{Shift from the Mechanistic Concept of the World to the Holistic}

Several major futurologists and visionaries talk about the transition from the entropic stage towards the syntropic stage of human civilisation. Currently, human civilisation is in the entropic stage, since it is primarily profit-oriented; transformation is connected with the human mind, and the mind is primarily connected with syntropy, creation of the new paradigms, and overcoming the entropy. [1] Satish Kumar sees the roots of the current global ecological crisis in the wrong system of values. In fact, the key idea of the modern industrial society is that people are superior to nature which is here for them, and they are here to manage and control it (humanocentrism, human supremacy). [2]

Such perception of ourselves needs to be changed for a few reasons; the most important being the fact that it could lead to our own annihilation. Sara Parkin argues that "what really is the driving force of the economic system is our value system." [1] [3]

Holistic interpretation of the current new economic reality served as the basis of the holistic economic theory and its key concepts [4]:

- Perception of economy as an open subsystem or an integral part of higher systems such as society, nature or universe;

- Perception of the global world economy as an indivisible whole, an implicated order; economic development is perceived as a holomovement;

- Perception of individual economic theories and theoretical schools and directions as fragmentary views developing the implications of a particular undivided reality; i.e. economics, as a science composed of individual partial economic theories complementing each other and creating a map of economic theories, where each has its own location, purpose, time and limits of performance, and no economic theory can be considered absolute;

- Change in perception of the economic processes reversibility in favour of their irreversibility, with an emphasis on economic dynamics rather than economic statics;

- Introduction of the concept of entropy, i.e. uncertainty or disorganisation, into economic theory; perception of its relation to the economic structure as a whole rather than using the notion of uncertainty only in relation to the decision-making and management of economic processes;

- Change of viewing the relation between information and economy and economic theory; understanding information as a structural factor generating the profile and the structure of the economics instead of viewing it exclusively in terms of the decision-making and management of economic processes; 
- Understanding the economy as a structure dissipating energy, raw materials, materials and information, while creating a structure around the attractors in the form of the factors determining the structure and profile of economy, society and civilisation; the value reorientation of a human and civilisation based on the holistic perception of the changed economic reality and respect for the world and natural laws;

- Understanding the emergence of the global economy as a chance to restore the original importance of economics as a science of management, while overcoming the alienation from its original meaning in the industrial age. In the global world economy, a person must behave first as an economist and only then as a trader or financier.

Fritjof Capra [15] argues that in terms of a systemic view, economy is a living system composed of living beings and social organisations in constant interaction with each other, while interacting simultaneously with the surrounding ecosystems on which they depend. Similar to individual organisms, ecosystems are self-organizing systems in which the animals, plants, microorganisms and inorganic components are interconnected by a complex network of interdependencies, including the mass and energy exchange in continuous cycles.

The holistic interpretation of the current changed economic reality and gradual development and articulation of the holistic economic theory can significantly contribute to changing the human activity on Earth and harmonizing people's relationship to nature. [5] The expanding global crisis of mankind gives rise to numerous economic theories aimed at harmonising economy with the new economic and civilisation reality, and thus sustaining the Earth's environment. [6]

\section{Spiral Management as part of System dynamics}

Spiral Management is based on the general theory of systems devised by Ilya Prigogine, a Belgian scientist. Inspired by his work and publications, and summarising the issue, Andrej Kopčaj wrote a comprehensive publication "Spiral Management". [7]

Ilya Prigogine who won the Nobel Prize for his contribution to non-equilibrium thermodynamics and his theory of dissipative structures in particular, in 1984 together with Isabelle Stengers published a book by the title "Order out of Chaos" and the subtitle "Man's new dialogue with nature", in which they presented their idea of the world development based on dissipative structures, second law of thermodynamics, and irreversible processes as sources of order generation. The futurist Alvin Toffler, in the preface to the Ilya Prigogin and Isabelle Stengers' book, introduces the Prigoginian paradigm. What Toffler thinks has made the Prigoginian paradigm particularly interesting is the shift of attention to those aspects of reality that characterise today's accelerated social change, such as disorder, instability, diversity, imbalance, non-linear relationships, and temporality (increased sensitivity to the time flow etc.). [7]

The essence of Spiral Management, as the name implies, is the so-called spiral growth, which can be understood as asymmetry of idea and symmetry of source; in other words: wise and unusual ideas and high integration of motivated promoters. The above-mentioned characteristics define the spiral growth of success as a result of the growing potential of success. The principle of spiral growth is ubiquitous in nature - the growth of galaxies in the universe, the growth of embryo in mother's womb, shape of hurricanes, the Milky Way or the DNA helical (spiral) structure. [7]

The effectiveness of spiral growth can be also observed e.g. in the evolution of trees. Instead of the energy-consuming pumping of water from the earth in the anti-gravity direction used by people, trees have developed a capillary rise, osmosis and evaporation. Similar examples of such evolutionary process can be found in many plant and animal species: every rule blocking the dynamics of spiral growth is compensated by many patterns strengthening its dynamics. [7]

Spiral Management is based on the continuous struggle of living systems for their own existence. Generally, it concerns the natural patterns of spontaneous development of the living and non-living systems. Spiral Management says that the goal of each system is its successful existence; to achieve a unique spiral (helical) growth, it is necessary to break the resistance of the average active balance culture and continue up to the critical (initial) point of the spiral growth. Neither failure to achieve the limit nor significant excess of the critical point will start the spiral growth. Being successful in terms of Spiral Management means to extricate from average and simultaneously not to go beyond the time and its needs. [7]

Spiral Management will not allow companies to "be abreast of the time" in the sense of building an ideal company respecting the moral, ethical, or socially sustainable principles. Using Spiral Management principles in business can, however, help avoid the mistakes that may consequently slow down the company development; i.e. to solve the issues before it becomes necessary. At the same time, it will help utilise natural laws and resources without disturbing or only minimally upsetting the fragile balance in nature, so that to eliminate the entropy emerging in the system and its environment. Just like in the nature.

\subsection{Entropy in Spiral Management}

Entropy is a status function of the second thermodynamic law, which expresses the tendency of all-natural processes towards unidirectionality. In terms of the related law, for example, it is impossible to transfer heat from a cooler body to a warmer one, but always vice versa. Entropy comes from a Greek word for transformation or direction of conversion; it is actually a measure of the tendency to the spontaneous heat convection, and, in combination with the first thermodynamic law, it forms the multiform world of equations that can describe the spontaneous direction of chemical reactions. [8] 
Entropy can be viewed as a molecular disorder. When two bodies, a hot and a cold, come into contact, they exchange heat. The originally warm body will record a loss of entropy, while the originally cold one will record an increase of entropy. The total entropy will, however, increase in both cases, since the energy degradation will result in a temperature drop. That means that everything in the universe is directed towards an increase of entropy, which grows along with chaos and disorder. [10] The law of the entropy growth says that spontaneous development of self-governed systems (left to themselves) exhibits tendency towards an increasing disorder. [11]

Entropy and its growth in nature, in a closed system of our environment, label our path to extinction and selfdestruction. In terms of energy, the use of non-renewable energy sources, nuclear energy and the means exceeding the natural balance represent a burden to the environment. The burden keeps rising together with entropy and chaos in the form of hurricanes, excessive heat, drought or rain. Nature itself does not know chaos, it has its firm order; it is us who introduce chaos along with the increase of entropy by utilising physical laws to extremes that are not inevitable. [10] The notion of entropy is used in physical chemistry or mathematics, as well as in biology, sociology and, most recently, in management. According to the second Prigogin Law, the prerequisite for existence of living systems is their ability to eliminate entropy by expelling it to the outer environment. [12] For management, entropy thus represents an unwanted phenomenon challenging the search for creative solutions to its minimisation. According to [8], entropy in management is characterised by:

- Rate of degradation,

- Rate of disorder of states and malfunction of processes,

- Rate of lack or inversion of information,

- Rate of the extinction probability.

\subsection{Corporate culture in Spiral Management}

Common management approaches utilise various economic theories and their applications in order to achieve the required economic indicators such as profit, cost optimisation, economic stability or competitiveness and performance. Spiral Management introduces a new concept into management, viewing a company as a system comprising two different subsystems:

- Technical subsystem - nonalive,

- $\quad$ Social subsystem - alive.

According to Kopčaj, corporate culture assures a "struggle for the existence" and the stability of any community, including that of enterprise. [9] Spiral Management views corporate culture as an artificial product of the human community (enterprise) with its key mission to cultivate the orientation of the ego-evaluation energy (EEE) of the individuals within the enterprise in favour of the growth of both components of the community (enterprise)'s wealth, i.e. its product and potential. Product is an objective component of wealth (product, service), while potential is a subjective one (probability of its effective transformation into product). [8] The technical subsystem comprises both, material (tangible) and intangible knowledge and processes, as well as the revitalisation of potential and its exploitation into the product. Fundamental enterprise processes or macro-processes comprise [9]:

- Marketing/Sales,

- Research/Development,

- Economy/Finance,

- Purchase/Storage,

- Production/Maintenance,

- Logistics/Informatics,

- Administration/Personnel Policy.

The social subsystem of an enterprise involves the ego-evaluation energy of employees. Its size is not directly proportional to the number of employees in the enterprise, but to the amount of integrated vital energy. Development and management of human resources means working with the energy units obtained to embellish wealth, rather than reckoning on the number of employees.

Various people have various goals which generally fall into two simple categories:

- To survive (assurance of existence),

- To enjoy (improvement of life quality).

If goals of an individual are contrary to the goals of enterprise, then energy of an individual will be egocentric and the individual will tend to behave according to the slogan: "Who does not steal, robs his own family." The opposite extreme is the complete harmonisation of both wealth components of an individual and enterprise; then the energy flow will be ethnocentric. Existence of an organization depends on whether it is energy or entropy what it acquires from its members. [9] 


\section{Spiral Management as Managerial Approach}

For management, it is essential to manage the organization unit that is deficient. Historically, the management of technical resources was the first to appear. In the distant past, there was a lack of material, such as stone (flint) in the Stone Age, bronze in the Bronze Age, iron in the Iron Age, production means in the Middle Ages, up to the lack of machinery in the Industrial Age. There was a lack of inanimate systems; people were just forced to work, usually based on fear. That worked for over 2,000 years. Then a management based on economic laws emerged. However, it only works in a static and stable environment, which, however, is no longer sufficient as a concept of the world or market.

In a dynamic turbulent environment, possibilities of economy and its laws are very limited. People have become a costly item. The current situation requires the management able to manage people in a turbulent and dynamic environment. Principally, all HR approaches agree that people need to be motivated to work; they need to develop their feeling of ownership and identify themselves with the goals of the enterprise. In such a way, an ordinary employee becomes an invaluable human asset that brings about the unique component of work that cannot be replaced even by robotics, i.e. creativity. In future, creativity and the ability to think ahead will be the key principles of the most successful businesses worldwide. [13] The problem of majority of the HR approaches, however, is measurability and manageability. Most managers act intuitively. A company may have a well-functioning remuneration system, implemented the optimal corporate culture and regular teambuilding, yet those cannot be directly measured and thus managed effectively. The managers can only state that the activity/event/measure was successful in the past and is likely to be improved in future. They cannot say, however, what, when, how much etc.

Spiral Management primarily addresses the management of a company's social system, as the only supplier of creative energy within the enterprise. This is logical, since it is people's energy that is utilised by businesses to meet their own goals. Spiral Management applies the laws of the living systems manageability, along with the theory of system stability, which serve as the fundamentals for the spiral management development as a unified and coherent theory.

From the Spiral Management's point of view, a manager has to achieve results in three areas of enterprise: [10]

1. Utilisation of potential and its transformation to product. This brings money.

2. Development of potential. This assures future.

3. Protection of potential. This reduces a risk of collapse/failure (e.g. maintenance of technical equipment, insurance).

For a manager, the ratio in which to address individual fields depends on the external environment and the state of enterprise.

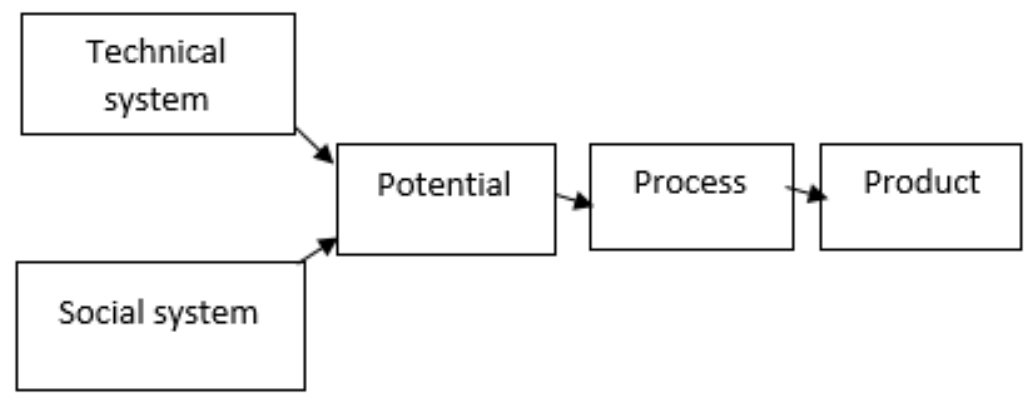

Fig. 1. Managerial Line [14]

At present, we can manage a product, process and technical potential of an enterprise at the maximum efficiency. Now, it is the time to master the management of social (human) potential (Figure 4). To manage anything, we have to divide it into parts that behave homogeneously, i.e. unambiguously respond to the steering impulse.

The level of energy and stability is dominant in terms of management, since it determines the degree of utilising other components and the result. Table 2 shows the classification of employees according to the degree of cooperation, their relationship to knowledge, the utilisation of their working time, the environment they work in and the work results they generate.

\begin{tabular}{|cllll|}
\hline Level & Knowledge & Processes (time) & Environment & Result \\
I. & produce & acquire spare time of others & abrupt changes & new fields \\
II. & apply & invest their spare time & continuous changes & improvement of position \\
III. & utilise & utilise work time & stable & maintaining position \\
IV. & misuse & do not utilise work time & destabilise & worsening position \\
V. & destroy & destroy within work time & destroy & drop out of competition \\
\hline
\end{tabular}

Table 1. Employees levels from the Spiral Management point of view [14] 
The key issues being dealt within Spiral Management are as follows:

1. The current situation in the world is characterised by high turbulence and instability.

2. It is necessary to gain profit (i.e. to control product) while developing and protecting one's own potential, the one represented by social system in particular.

3. Creativity of employees should be controlled.

4. Both teams and individuals should be controlled.

5. The most effective methods and tools should be selected.

6. There's no time for the "attempt - error" method. Instead, act immediately and effectively.

That means it is high time for companies to master the social system management based on their own actual energy and stability level. It is a role of line managers. The line managers are not any more the smartest ones in terms of technology. It is the executive officers who are more competent in their fields since they have competencies, authorisations and certificates. Line managers have to adopt a role of preparing the environment and energy of social system. They have to learn how to motivate individuals and teams, and shape their qualities and personalities.

\section{Scientific Prospects of Spiral Management}

From the scientific point of view, it is essential whether we only want to explore and describe the past, or to make reasonable forecasts for the future. Social research is mostly oriented on the past. Forecasts for the years to come are limited to extrapolation in the same conditions.

The area of the social systems management is extremely promising for practical application. Management is supposed to take appropriate measures today in order to achieve the desirable results in the future. This, however, requires sufficiently precise and quantified development patterns and managerial techniques. Until now, the social systems used mainly the knowledge of sociology and psychology, quantifiability of which is quite limited, and thus the accuracy of managerial decisions is inadequate. It is the area very desirable to develop. Spiral Management has the potential to be successful even in research, ideally combining several disciplines, particularly management, sociology, psychology, biology, anthropology and pedagogy. In terms of successful management of social systems, strict separation of individual sciences should be replaced by the holistic approach combining several scientific disciplines.

\section{Discussion}

In the future, Spiral Management principles can be applied in managing individual employees (as mentioned above) as well as managing performance of various generations of employees. Companies started considering generations in the mid-20th century, when the first sociologists noticed certain personal differences between the people born before and after the World War II. Later, several sociological and anthropological theories dividing the human population into generations according to their most distinctive features were developed. From the managerial point of view, the basic question is: "How can be various generations of employees in various organisations managed effectively?"

The current labour market is to face a unique situation: five different generations of employees will be working side by side within an organization: Traditionalists, Baby Boomers, Generation X, Generation Y and Generation Z. The labour market conditions (along with the lack of specific labour workforce in developed countries) call for the need to manage individual generations of employees in the work process. Conventional approaches describe a wide scale of the skills, knowledge and experience required; sometimes including psychological traits. When combining these features, managers may be confronted with a precarious unmanageable situation.

Spiral Management can provide solutions by using so-called theory of developmental cycles [9]. Within the cyclical exploration of the human society, Kopčaj defined individual stages and certain rules of development (about 105,000 years ago up to the present), plotting a timeline (time axis). Built on the natural mathematical constants (Golden ratio, Feigenbaum constant), the axis expresses the time shortening of each subsequent development stage, generally just like in the case of other living systems in nature. If applying the phenomenon to the development of human generations, we find that the curve (i.e. the time limits of generations) of generations keeps decreasing.

The research of five different generations of employees is just carried out. We are collecting data for analysis from more than 10000 slovak companies and organizations. The main theme of our research is to find out how to effectively manage each generation of employees, what are their motivators and needs, if they can or cannot cooperate and what is the "right" approach towards each generation of employees. The results will be available in the end of 2018. Our goal is to bring the results for each company participating in our research and that is why we have used the Spiral Management Methodology to uncover the secrets of human capital systems within companies and organizations.

\section{Conclusion}

The manager's job is to ensure that people know how to work and want to work at the highest level of energy. This subsystem, however, cannot be effectively managed purely by making intuitive decisions. In order to be able to manage, we need to know the system to be managed and the way of how to influence it. 
Spiral Management combines the knowledge from a variety of disciplines (psychology, anthropology, biology, mathematics, physics, management, etc.), providing a "manual" for managing a social subsystem in an enterprise. Such approach is unique since it can be mathematically quantified, and the dependencies of individual factors with respect to sustainability or increase of the company's success potential can be measured.

If the object of management is a human being or a social group, the management theories should provide an effective methodology to ensure effective management. The role of scientific research should be to design a system that will be universally valid, generally applicable and effective, while taking into account the time factor in the sense of the constant need for change and in the sense of the time relativity.

\section{References}

[1] Erban, V. (2003). New paradigm? From mechanistics to holistics, from part to whole. In UNImagazín. XIII. roč. University of South Bohemia in České Budějovice, 2003 (pp. 31-34). ABOPRESS. Retrieved from http://www2.tf.jcu.cz/ erban/paradigma.pdf

[2] Kumar, S. (2014). No Destination: Autobiography of a Pilgrim. (4th Edition). Green Books, Cambridge.

[3] Parkin, S. (1991). Green Future. Agenda for 21st Century. Fount, London.

[4] Klinec, I. (2011). The Outline of the Holistic Economics Theory. Economic Institute of the Slovak Academy of Sciences, Ekonomic theory, Prognostics (futurology).

[5] Henderson, H. (1991). Paradigms in Progress. Life Beyond Economics. Knowledge Systems. Inc., Indianopolis Paradigms in Progress. Berrett-Koehler Publishers.

[6] Gore, A. (1992). Earth in the Balance. Ecology and the Human Spirit. Houghton Mifflin Company, Boston.

[7] Kopčaj, A. (2007). Spiral management. Alfa, Bratislava.

[8] Kopčaj, A. (1997). Multiplying the Wealth. Kopčaj - Silma '90. Ostrava. pp. 12-16.

[9] Kopčaj, A. (1999). Management of Change - The common way how to achieve extraordinary development. Grada Publishing, Prague.

[10] Skácel, D. (2002). What is it the entropy? In Alternativní energie 1/2002. CEMC - České ekologické manažerské centrum. Retrieved from http://www.tzb-info.cz /casopisy/alternativni-energie.

[11] Šimon, P. (2015). Entropia - málo chápaná fyzikálna veličina s vel’kým dosahom. (The Entropy - not really understood quantity with a huge impact.) In EnergeticaWeb. Retrieved from https://www.energiaweb.sk/2015/12/09/entropia-malo-chapana-fyzikalna-velicina-s-velkym-dosahom/

[12] Plchová, J. (2013). New approaches to human resources management in the firm. In Journal of knowledge society. $1 / 2013$ (1), pp. $1-8$

[13] Lockwood, N. R. (2005). Crisis Management in Today’s Business Environment. USA: Society for Human Resource Management.

[14] Polakovič, L'., \& Krempaský, J. (2012). Quantitative management theory of enterprises as unimodal systems. In ATP Journal, 19, pp. 44-46.

[15] Capra, F. (1982). The Turning Point: Science, Society and the Rising Culture. Flamingo Press, 1990 Edition. 